\title{
Microchimerism and allogeneic transplantation
}

\section{We need the proof in the pudding}

Koen van Besien, ${ }^{1, *}$ Hong-Tao Liu ${ }^{2}$ and Andrew Artz ${ }^{2}$

${ }^{1}$ Weil Cornell Medical College; New York City, NY USA; ${ }^{2}$ University of Chicago; Chicago, IL USA

Keywords: microchimerism, stem cell transplant, umbilical cord transplant, NIMA, IPA

Submitted: 02/25/13

Accepted: 03/08/13

http://dx.doi.org/10.4161/chim.24358

*Correspondence to: Koen van Besien;

Email:kov9001@med.cornell.edu

Addendum to: Van Besien K, Liu H, Jain N, Stock W, Artz A. Umbilical Cord Blood Transplantation Supported by Third-Party Donor Cells: Rationale, Results, and Applications. Biol Blood Marrow Transplant 2012; S1083-8791(12)00463-6.; PMID:23142329;

http://dx.doi.org/10.1016/j.bbmt.2012.11.001
A llogeneic stem cell transplantation (SCT) is the most effective treatment for leukemia and mediates its therapeutic effect to a large extent through immunologic effects, the socalled graft-vs-leukemia effects. Though highly effective it remains wrought with complications including opportunistic infections, graft vs. host disease as well as failure due to disease recurrence. Early animal experiments established that an HLA identical donor was a prerequisite for allogeneic SCT. ${ }^{1}$ But HLA-identical donors are elusive in societies where the number of siblings is decreasing and as scientists discover an ever larger number of HLA polymorphisms. ${ }^{2}$ Methods of transplantation that overcome HLA barriers are under intense investigation. HLA-mismatched Umbilical cord blood (UCB) is increasingly used as a source of stem cells for HLA-mismatched allogeneic stem cell transplantation (SCT) and has unique features that could be manipulated to advance the field. UCB-SCT causes limited GVHD, compared with cells from adult donors and relapse rates of leukemia are relatively low after UCB SCT, suggesting that UCB-SCT mediates GVL through mechanisms that are separate from those that cause GVHD., ${ }^{3,4}$ In our recent article we review recent data on fetal immunology and UCB SCT that provide a plausible explanation for this clinical observation. ${ }^{5}$

It has long been known that exposure of a fetus to foreign antigens, be it from a fraternal twin, or from the mother can lead to lifelong tolerance. ${ }^{6,7}$ The low rate of GVHD associated with UBC SCT is reminiscent of this fetal tolerance and is perhaps best understood in the context of the makeup of the fetal immune system. Mold and McCune showed that the fetal immune system is dominated by $\mathrm{T}$ regulatory cells with suppressive activity. ${ }^{8}$ Fetal tolerance is most pronounced to maternal antigens and then specifically to the highly immunogenic non-inherited maternal HLA antigens or NIMAs. ${ }^{9}$ Van Rood et al. were the first to speculate that exposure of UCB grafts to an HLA mismatched transplant recipient whose mismatched HLA antigens were identical to the maternal NIMA antigens of the UCB would result in superior outcomes. Two large studies of different data sets support this hypothesis. ${ }^{10,11}$ Transplantation of an UCB graft into a mismatched recipient expressing NIMA, results in superior outcomes compared with transplant into a recipient who doesn't express NIMA.

Another important aspect of the fetal immune system is the presence of maternal microchimeric cells. ${ }^{12}$ These maternal cells are sensitized to the fetal antigens of paternal origin, the so called IPA or inherited paternal antigens. Van Rood et al. again speculated that exposure to those IPA's in a transplant recipient would allow the microchimeric maternal cells to target recipient cells. They provide powerful indirect evidence that this is indeed the case. ${ }^{13}$ Recipients whose HLA type includes the UCB donor's IPA have a lower rate of disease recurrence than those whose HLA type does not include those IPAs. This hypothesis would be further supported by a direct demonstration of maternal cells in UCB. Previous studies have demonstrated maternal cells 
in many stillborn fetuses and in variable percentages of UCB units, ranging from $20 \%$ to, in one series $100 \% \cdot{ }^{14,15}$ But the proof will be in the pudding: the demonstration of cells in the transplant recipient that originate from the UCB's mother and that directly mediate GVL effects. Demonstrating such cells may be possible with increasingly sensitive methods.

With knowledge of maternal and fetal HLA one could choose a donor who recognizes NIMA and targets IPA in a recipient. To do so in a prospective fashion might result in a drastic improvement in outcomes of UCB stem cell transplant. But there are several hurdles, including the lack of maternal HLA typing for many of the UCB units currently in banks, the erratic hematopoietic recovery of UCB stem cell transplant and the limited supply of UCB stem cell grafts. ${ }^{2}$ Each of these can at least in theory be addressed. Maternal HLA typing can be obtained from maternal serum samples which are routinely stored in UCB units. ${ }^{16}$ Erratic and delayed hematopoietic recovery can be addressed in part by UCB expansion, but perhaps more easily by the technique of haplo cord transplantation in which UCB units are co-infused with mobilized peripheral blood stem cells from a mismatched family (haplo) donor. ${ }^{17}$ The haplo graft provides rapid hematopoietic reconstitution, but it is $\mathrm{T}$ cell depleted and over time is routinely outcompeted by the UCB unit which assures durable long-term hematopoiesis. The last problem is that of lack of UCB units which are at the same time sufficiently well matched, and contain sufficient cells for transplant. ${ }^{2}$ Using the haplo cord transplant approach one may be able to obtain durable engraftment with smaller UCB units, a hypothesis which we are currently prospectively testing.
Acceptance of units with a smaller cell dose would drastically expand the available inventory, particularly for patients of ethnic minority descent. Numerous technical hurdles remain, but we believe that an integration of insights from fetal immunology combined with careful clinical and correlative studies will benefit the field of UCB stem cell transplant.

\section{Disclosure of Potential Conflicts of Interest}

No potential conflicts of interest were disclosed.

\section{References}

1. Thomas ED. A history of haemopoietic cell transplantation. Br J Haematol 1999; 105:330-9; PMID:10233401; http://dx.doi.org/10.1111/j.13652141.1999.01337.x.

2. Gragert L, Maiers M, Williams E, Confer D, Klitz W. Modeling effective patient-donor matching for hematopoietic transplantation in United States populations [abstract]. Hum Immunol 2010;S114.

3. Brunstein CG, Gutman JA, Weisdorf DJ, et al. Allogeneic hematopoietic cell transplantation for hematological malignancy: relative risks and benefits of double umbilical cord blood. Blood 2010; http:// dx.doi.org/10.1182/blood-2010-05-285304.

4. Eapen M, Rocha V, Sanz G, Scaradavou A, Zhang MJ, Arcese W, et al.; Center for International Blood and Marrow Transplant Research; Acute Leukemia Working Party Eurocord (the European Group for Blood Marrow Transplantation); National Cord Blood Program of the New York Blood Center. Effect of graft source on unrelated donor haemopoietic stem-cell transplantation in adults with acute leukaemia: a retrospective analysis. Lancet Oncol 2010; 11:653-60; PMID:20558104; http://dx.doi. org/10.1016/S1470-2045(10)70127-3

5. Van Besien K, Liu H, Jain N, Stock W, Artz A. Umbilical Cord Blood Transplantation Supported by Third-Party Donor Cells: Rationale, Results, and Applications. Biol Blood Marrow Transplant 2012; S1083-8791(12)00463-6; PMID:23142329.

6. Owen RD, Wood HR, Foord AG, Sturgeon P, Baldwin LG. Evidence for Actively Acquired Tolerance to Rh Antigens. Proc Natl Acad Sci U S A 1954; 40:420-4; PMID:16589498; http://dx.doi. org/10.1073/pnas.40.6.420.

7. Owen RD. Immunogenetic consequences of vascular anastomoses between bovine twins. Science 1945; 102:400-1; PMID:17755278; http://dx.doi. org/10.1126/science.102.2651.400.
8. Mold JE, McCune JM. Immunological Tolerance During Fetal Development. Advances in Immunology.: Elsevier; 2012:73-111.

9. Claas FH, Gijbels Y, van der Velden-de Munck J, van Rood JJ. Induction of B cell unresponsiveness to noninherited maternal HLA antigens during fetal life. Science 1988; 241:1815-7; PMID:3051377; http:// dx.doi.org/10.1126/science.3051377.

10. Rocha V, Spellman S, Zhang MJ, Ruggeri A, Purtill D, Brady C, et al.; Eurocord-European Blood and Marrow Transplant Group and the Center for International Blood and Marrow Transplant Research. Effect of HLA-matching recipients to donor noninherited maternal antigens on outcomes after mismatched umbilical cord blood transplantation for hematologic malignancy. Biol Blood Marrow Transplant 2012; 18:1890-6; PMID:22814031; http://dx.doi.org/10.1016/j.bbmt.2012.07.010.

11. van Rood JJ, Stevens CE, Smits J, Carrier C, Carpenter C, Scaradavou A. Reexposure of cord blood to noninherited maternal HLA antigens improves transplant outcome in hematological malignancies. Proc Natl Acad Sci U S A 2009; 106:199527; PMID:19901324.

12. Burlingham WJ, Nelson JL. Microchimerism in cord blood: mother as anticancer drug. Proc Natl Acad Sci U S A 2012; 109:2190-1; PMID:22323582; http:// dx.doi.org/10.1073/pnas.1120857109.

13. van Rood JJ, Scaradavou A, Stevens CE. Indirect evidence that maternal microchimerism in cord blood mediates a graft-versus-leukemia effect in cord blood transplantation. Proc Natl Acad Sci U S A 2012; 109:2509-14; PMID:22232664; http://dx.doi. org/10.1073/pnas.1119541109.

14. Scaradavou A, Carrier C, Mollen N, Stevens C, Rubinstein P. Detection of maternal DNA in placental/umbilical cord blood by locus-specific amplification of the noninherited maternal HLA gene. Blood 1996; 88:1494-500; PMID:8695871.

15. Petit T, Gluckman E, Carosella E, Brossard Y, Brison O, Socié G. A highly sensitive polymerase chain reaction method reveals the ubiquitous presence of maternal cells in human umbilical cord blood. Exp Hematol 1995; 23:1601-5; PMID:8542953.

16. Cotton LA, Abdur Rahman M, Ng C, Le AQ, Milloy MJ, Mo T, et al. HLA class I sequence-based typing using DNA recovered from frozen plasma. J Immunol Methods 2012; 382:40-7; PMID:22584155; http:// dx.doi.org/10.1016/j.jim.2012.05.003.

17. Liu H, Rich ES, Godley L, Odenike O, Joseph L, Marino S, et al. Reduced-intensity conditioning with combined haploidentical and cord blood transplantation results in rapid engraftment, low GVHD, and durable remissions. Blood 2011; 118:6438-45; PMID:21976674; http://dx.doi.org/10.1182/blood2011-08-372508. 